\author{
María Eugenia Pérez González y María Pilar García Rodríguez \\ Departamento de Análisis Geográfico Regional y Geografía Física. Universidad Complutense de Madrid
}

\title{
Fluctuaciones hídricas de la laguna de Gallocanta analizadas a partir de teledetección
}

\section{Resumen}

El análisis multitemporal de imágenes de satélite y la disponibilidad de datos de campo permiten conocer las amplias fluctuaciones hídricas de la laguna de Gallocanta y las variaciones medioambientales de este humedal. El incremento de las precipitaciones entre 2003 y 2010 pone fin al largo periodo de sequía, que llega a desecar la laguna durante años y facilita la recuperación de la lámina de agua a niveles similares a los años ochenta. A partir de las imágenes Landsat la laguna de Gallocanta es claramente identificable en cualquier fecha, aunque presente fases de inundación (1987, 2009 y 2010) y desecación muy marcadas (2000 y 2001) correspondientes a años húmedos y secos.

\section{RÉsumÉ}

L'analyse multitemporelle de l'imagerie satellitaire et la disponibilité de données sur le terrain nous permettent de connaître les fluctuations dans l'eau de la lagune de Gallocanta et les variations de l'environnement de cette zone humide. L'augmentation des précipitations entre 2003 et 2010 met fin à la longue période de sécheresse qui a séché la lagune depuis des années et facilite la récupération de la surface de l'eau à des niveaux similaires aux années quatre-vingt. En images Landsat la

$L$ a laguna de Gallocanta, localizada entre Zaragoza y Teruel, es el humedal interior más grande de España y uno de los más importantes de Europa occidental (Fig. 1). Las oscilaciones de su lámina de agua alcanzaron niveles muy bajos a principios del siglo Xxi, lo que dio lugar a diferentes hipótesis sobre su posible desecación en

\footnotetext{
* Agradecemos la información facilitada por la Confederación Hidrográfica del Ebro sobre los niveles piezométricos y datos meteorológicos.

Este trabajo forma parte del proyecto CSO2012-34785.
}

lagune de Gallocanta est clairement identifiable à tout moment, mais elle a des étapes d'inondation (1987, 2009 et 2010) et de séchage très marquées (2000 et 2001) pour les années humides et sèches.

\section{AbSTRACT}

Multitemporal analysis of satellite images and field data availability allow us to know the wide fluctuations in water of the Gallocanta wetland and environmental variations of this wetland. The increase in rainfall between 2003 and 2010, ending the long period of drought, dry reaching the wetland for years and facilitates the recovery of the water surface at levels similar to the eighties. From the Landsat images Gallocanta wetland is clearly identifiable at any time, although this stage of flooding (1987, 2009 and 2010) and drying very marked (2000 and 2001) for wet and dry years.

Palabras Clave/Mots clé/Keywords

Teledetección, Gallocanta, ciclo hidrológico, humedal. Télédétection, Gallocanta, cycle hydrologique, zones humides. Remote sensing, Gallocanta, hydrological fluctuations, wetland.

relación al cambio climático global. La Confederación Hidrográfica del Ebro (Chebro) ha recopilado datos sobre la altura de la lámina de agua desde los años setenta a la actualidad que permiten conocer mejor la variabilidad hídrica temporal de este humedal. El objetivo del estudio es relacionar estos datos con los obtenidos a partir de imágenes de satélite con el fin de conocer mejor las posibles tendencias o ciclos hídricos de la laguna.

El carácter salobre del humedal puede inducir a errores en la interpretación realizada exclusivamente me- 


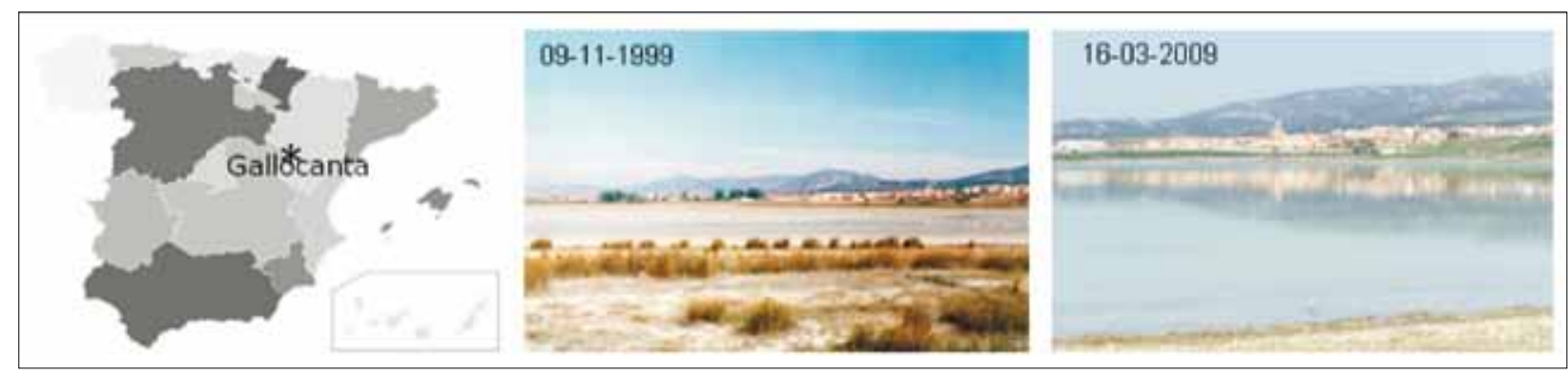

FIG. 1. Localización de Gallocanta y fotografías de la laguna. El 09-11-1999 la laguna está seca y con eflorescencias salinas, aunque la humedad edáfica simula la presencia de agua superficial, a modo de espejismo. El 16-03-2009 Gallocanta ha recuperado niveles de agua similares a los de décadas pasadas.

diante los datos de satélite, por lo que se hace imprescindible el conocimiento de la verdad terreno (García y otros, 2006). A pesar de ello la teledetección resulta una técnica muy útil para conocer la variabilidad espacio temporal de humedales continentales (Jong, 1994; Quingxi y otros, 1997; Koch y otros, 2001; Dehaan y Taylor, 2002; Reese y otros, 2002; Schmid, 2004; Castañeda y Herrero, 2009; Pérez y otros, 2009).

\section{MATERIALES Y MÉTODOS}

Se analizan las variaciones espaciales y temporales de la laguna de Gallocanta a partir de imágenes y datos de campo. El área de estudio corresponde a las escenas Landsat (sensores TM y ETM) $20031 / 32$ y se han seleccionado catorce fechas que recogen los diferentes estados hídricos del gran humedal interior (laguna de Gallocanta) y otras lagunas menores (La Zaida, laguna Grande y laguna Pequeña). Estas imágenes corresponden a distintas estaciones del año (primavera, verano y otoño) para poder establecer comparaciones intraanuales e interanuales sobre la cantidad y calidad de las aguas. Aunque se dispone de imágenes de otros satélites (Noaa y Spot) la resolución espacial del Landsat es idónea para analizar este humedal, que tiene una longitud máxima de $7,7 \mathrm{~km}$ y una anchura máxima de 2,8 km, con un área total de $14,4 \mathrm{~km}^{2}$ (Gracia Prieto, 2009).

El conjunto de imágenes Landsat se han obtenido del Programa de la Nasa (Global Land Cover Facility), del Plan Nacional de Teledetección del IGN y adquiridas al INTA y se han procesado con el programa Erdas Imagine 2010. Estas imágenes han sido georreferidas a coordenadas geográficas y se le han aplicado correcciones atmosféricas y geométricas. Para identificar las características principales de la laguna y resaltar su variabilidad espacio-temporal se han realizado mejoras radiométricas y espectrales.
Se analizan visualmente las imágenes con diferentes combinaciones de bandas en color natural (3-2-1, R-V-A) y falso color (4-3-2, 5-4-2; 5-4-3; 7-5-4 y 4-5-7, R-VA), para detectar en cada fecha las superficies cubiertas de sales, la humedad edáfica y la lámina de agua. Otras mejoras espectrales que permiten discriminar diferentes cubiertas del suelo son el índice de vegetación de la diferencia normalizada (NDVI) y el de hue (tono), saturación e intensidad de color (HSI) (Chuvieco, 2006). Estas mejoras espectrales también han ofrecido buenos resultados en otros humedales (Hodgson y otros, 1987; Patience y Klemas, 1993; Dwivedi y otros, 1999; Al-Khaier, 2003).

En cada una de las imágenes se han realizado perfiles espectrales de las bandas visibles e infrarrojos (próximo y medio) en dos sectores de la laguna. Estos se han seleccionado atendiendo a los puntos con lámina de agua más profunda y a los más secos.

Con el fin de resaltar las principales características de la laguna de Gallocanta y su entorno se han seleccionado tres fechas contrastadas para realizar una clasificación supervisada, atendiendo al algoritmo de máxima probabilidad.

Para completar el estudio se han analizado los datos facilitados por la Confederación Hidrográfica del Ebro sobre niveles piezométricos, datos de aforos y climáticos del periodo 1979-2011. Toda esta información se ha relacionado con los datos aportados por los satélites.

\section{RESULTADOS Y DISCUSIÓN}

Lo primero que cabe destacar es el distinto periodo de muestreo sobre las variaciones hídricas de la laguna de Gallocanta en las diferentes fuentes analizadas. Las imágenes de satélite comprenden desde 1987 a 2011 y se seleccionaron catorce fechas de estaciones y años contrastados, a fin de recopilar la mayor variabilidad de la 
CUADRO I. Imágenes seleccionadas

\begin{tabular}{|ccccl|}
\hline Satélite & Sensor & Escena & Fecha & \multicolumn{1}{c|}{ Estación } \\
\hline Landsat & TM & $200-32$ & $14-04-1987$ & Primavera \\
Landsat & TM & $200-31$ & $17-06-1987$ & Primavera/verano \\
Landsat & TM & $200-$ flotante & $30-03-1999$ & Primavera \\
Landsat & TM & $200-$ flotante & $03-07-1999$ & Verano \\
Landsat & TM & $200-$ flotante & $09-11-1999$ & Otoño \\
Landsat & ETM & $200-31$ & $30-07-2000$ & Verano \\
Landsat & ETM & $200-32$ & $30-05-2001$ & Primavera \\
Landsat & TM & $200-32$ & $18-06-2005$ & Primavera/verano \\
Landsat & TM & $200-32$ & $24-10-2005$ & Otoño \\
Landsat & TM & $200-31$ & $25-03-2009$ & Primavera \\
Landsat & TM & $200-31$ & $29-04-2010$ & Primavera \\
Landsat & TM & $200-31$ & $18-07-2010$ & Verano \\
Landsat & TM & $200-31$ & $22-10-2-10$ & Otoño \\
Landsat & TM & $200-31$ & $05-07-2011$ & Verano \\
\hline
\end{tabular}

Fuente: Elaboración propia.

lámina de agua. A su vez, la Confederación Hidrográfica del Ebro viene registrando la altura de agua de Gallocanta desde los inicios de mayo de 1974 hasta la actualidad. De los primeros veinte años se tienen datos cada cinco días y de los diecisiete últimos (1995-2011, inclusive) casi diarios, por lo que existe simultaneidad de registros satelitales y de campo. Esta disponibilidad de información permite relacionar con precisión los análisis visuales y digitales de las imágenes con la columna de agua real de la laguna. En la figura 2 se recogen esta altura del agua, su curva de tendencia polinómica y las fechas correspondientes a las imágenes con la laguna más seca y más húmeda de los últimos veinticinco años (1987-2011). De esta información cabe destacar (Fig. 2):

- Los máximos niveles de agua, superiores a 1,20 m de altura, se produjeron en los años setenta (con un máximo de 2,24 m en mayo de 1974) y, desde julio de 1980, no se alcanzan alturas similares. Esto da lugar a que cualquier línea de tendencia sea muy descendente, pues los valores por encima de 1,5 metros no ha vuelto a repetirse hasta la fecha (Comín y otros, 1992; Gracia Prieto, 1993 y 2009).

- La laguna ha llegado a desecarse durante varios meses en las décadas de 1980 (1983, 1985 y 1987) y 1990 (1995 y 1996), pero, sin duda, el periodo seco más largo hasta ahora ha sido desde julio de 1998 hasta mayo de 2002, en los que la laguna se mantuvo con menos de $5 \mathrm{~mm}$ de altura

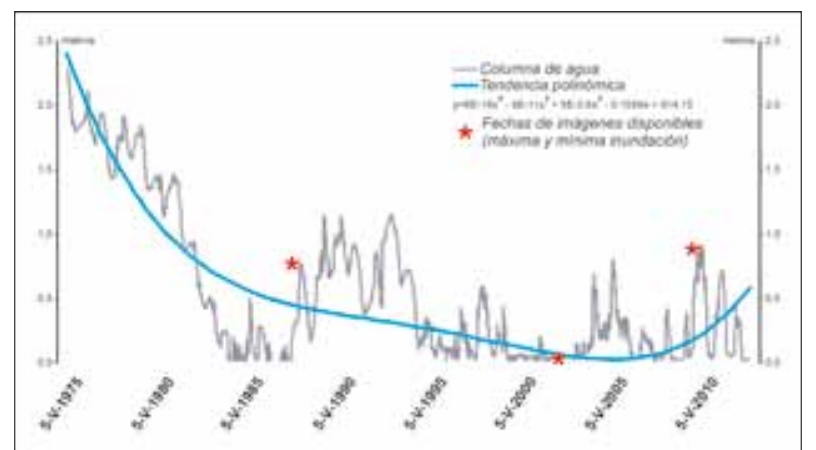

FIG. 2. Datos de la columna de agua de Gallocanta y línea de tendencia (polinomial, orden 4). Fuente: Confederación Hidrográfica del Ebro, 2011, y elaboración propia.

de agua, casi de forma permanente durante casi cuatro años. Sin embargo, estos mínimos valores vuelven a modificarse a partir de 2003 , en que Gallocanta recupera valores propios de finales de los años ochenta.

- En conjunto los datos se ajustan al $99 \%$ de confianza a una función de regresión polinomial de orden 4, que explica el 76,84\% de la variabilidad temporal de la lámina de agua, con un error estándar de 0,25. Esta función señala una leve tendencia reciente al incremento del agua de la laguna, si bien las mayores extracciones del agua subterránea para los cultivos hacen difícil la recuperación de los niveles de agua de años precedentes.

La información ofrecida por las imágenes de satélite sobre distintos canales de espectro electromagnético permite componer imágenes en color natural, falsos colores e imágenes obtenidas mediante distintas operaciones de sus valores espectrales. A partir de ellas se analizan las principales variaciones espaciales y temporales de la laguna de Gallocanta. De todas las imágenes analizadas en el estudio se han seleccionado tres de fechas contrastadas para ver la evolución de la lámina de agua superficial: máxima inundación (1987 y 2009) y mínima (2001)

Las imágenes en color natural (3-2-1, en los cañones de color R-G-B) muestran notables cambios en la superficie inundada e inundable y en la extensión de las eflorescencias salinas. Los más señalados son:

- El vaso lagunar de Gallocanta es claramente identificable en cualquier fecha, con un contorno bien definido, aunque los últimos veinticuatro años ha registrado fases de inundación $(1987,2009$ y 2010) y desecación muy marcadas (2000 y 2001). 


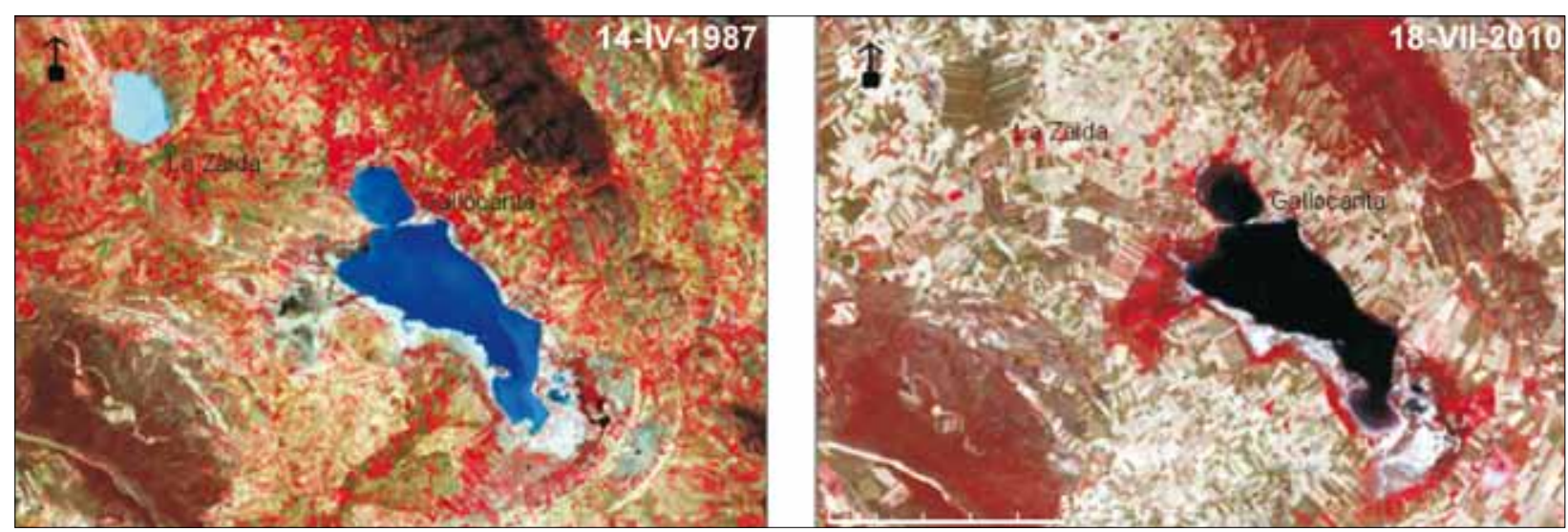

FIG. 3. Imágenes Landsat, falso color 4-3-2 (R-V-A). Estas imágenes muestran la laguna de Gallocanta cubierta de agua en años anteriores y posteriores a la sequía de finales del siglo xx y principios del xxı. Los diferentes tonos de azul indican variaciones del nivel de agua, más profunda cuanto más oscuros. Desde 2009 Gallocanta ha recuperado niveles de agua similares a los que tenía en los años ochenta. En la imagen de 1987 la laguna de La Zaida presenta una lámina de agua somera, frente al 2010 en la que todo el vaso lagunar está cultivado.

La laguna de la Zaida, al norte de Gallocanta, tiene cambios más importantes ya que además se somete a explotación agrícola en régimen de año y vez. Cuando no está cultivada mantiene una somera lámina de agua.

- Las surgencias kársticas, «ojos», situados al norte y noroeste de la laguna (pequeñas manchas circulares muy oscuras), se identifican en algunas fechas cuando la laguna está bastante seca. En las imágenes de los años más húmedos, al tener mayor cantidad de agua, las surgencias se confunden con el terreno inundado del borde lagunar.

- Las imágenes de los primeros años del siglo XXI reflejan la intensa sequía acaecida durante la década de 1990 y primeros años del siglo actual. Casi todo el vaso lagunar de Gallocanta está seco en superficie, de color muy blanco debido a la alta reflectividad de las eflorescencias salinas. Llama la atención la dificultad de delimitar la laguna de la Zaida, pues a la ausencia de agua se le une su explotación agrícola, por lo que es complejo discriminarla visualmente de los cultivos de su entorno en esta combinación de bandas.

- La imagen en color natural 3-2-1 confunde los suelos saturados con los que tienen sales en superficie: Laguna de La Zaida y borde de Gallocanta, por lo que es preferible la utilización de canales infrarrojos.

De las distintas imágenes en falso color se ha seleccionado la combinación 4-3-2 (R-G-B) correspondiente a los canales del infrarrojo próximo, rojo y verde (Fig. 3 y 4). Del análisis de esta combinación destaca:

- La imagen más reciente de verano (2010) es la que refleja mejor las distintas lagunas con superficies y alturas de agua contrastadas. Esto se produce por la mayor extensión y volumen de agua en todas las lagunas, incluso superiores a las de finales de los años ochenta del siglo xx disponibles. La diferencia altimétrica entre una fecha y otra es de unos $15 \mathrm{~cm}$ (70 y $55 \mathrm{~cm}$ respectivamente) y la distinta reflectividad de la lámina de agua permiten discriminar dichas diferencias.

- En la figura 3, con imágenes de años muy húmedos (1987 y 2010) la laguna de Gallocanta aparece en color negro o azul muy oscuro lo que indica la profundidad del agua, con una altura de unos 70 a $80 \mathrm{~cm}$ y en azul claro las laguna somera de La Zaida (imagen de 1987), con unos 30-40 cm.

- Los suelos cubiertos por eflorescencias salinas sólo pueden apreciarse en las imágenes de satélite durante el mínimo hídrico, que se extiende de verano a otoño y en años muy secos (Fig. 4). Destaca la imagen de noviembre con toda la laguna blanquecina y, además, representa el mínimo anual, propio de la sequía acaecida y del carácter kárstico de la laguna. Las imágenes de 2000 y 2001 también reflejan la ausencia de agua y la presencia de numerosas eflorecencias salinas, aunque la humedad retenida en el suelo hace que aparezca, gran parte del vaso lagunar, en to- 
nos azules, tanto más oscuros cuanto mayor es la humedad. Esto es debido a que las imágenes que utilizan el infrarrojo cercano (bandas 5 y 4 del TM y ETM) pueden inducir a errores de interpretación en cuanto a la existencia de agua superficial, confundiendo suelos saturados con láminas de agua. Este error puede darse incluso in situ, observando la laguna desde sus márgenes, pues la humedad edáfica producen el efecto visual de espejismo, cuando en realidad no hay lámina de agua superficial. En estas fechas La Zaida aparece en tonos verdosos o rosados debido a que está cultivada.

Otra combinación de bandas bastante útil es la 5-4-3 (R-V-A), ya que permite cartografiar la superficie ocupada por humedales incluso de pequeño tamaño y el área de inundación de la laguna de Gallocanta (colores azul oscuro y azul claro respectivamente).Otras imágenes en falso color en las que se combinen sólo canales infrarrojos (7-5-4 o 4-5-7) sirven para cartografiar cualquier laguna pues aparecen todas en color negro; sin embargo, la exclusión de canales del espectro visible no permite distinguir diferentes espesores de agua, ni variaciones en la calidad de la misma (García y Pérez, 2001).

De las diferentes imágenes obtenidas mediante operaciones con los valores digitales (mejoras espectrales) cabe destacar las del índice de vegetación de la diferencia normalizada (NDVI, banda 4-banda3/banda4+-banda3). En cualquier fecha el NDVI tiene valores muy bajos, por lo que todos los humedales aparecen bien delimitados en color negro. Esto se produce por un contenido elevado de agua o humedad edáfica y baja actividad clorofílica, característica de humedales no contaminados. Así Gallocanta se identifica bien con independencia de estar seca o inundada y no muestra síntoma alguno de contaminación ni eutrofización. El NDVI también permite conocer la distribución y cuantía de los cultivos de regadíos del entorno de Gallocanta (color blanco). Probablemente estos regadíos captan el agua del mismo acuífero que alimenta a Gallocanta, por lo que se reduce aún más su alimentación subterránea. A su vez, permite reconocer el vaso lagunar de La Zaida por su patrón espacial, con parcelas de cultivo.

Las imágenes obtenidas mediante el NDVI no son aconsejables para identificar humedales pequeños, pues se confunden frecuentemente con parcelas de regadío. Sin embargo, este índice ha permitido diferenciar grados de desarrollo de la vegetación y, en ausencia de ésta, grados de humedad en el suelo (Díaz de Arcaya y otros, 2005). (Fig. 5)
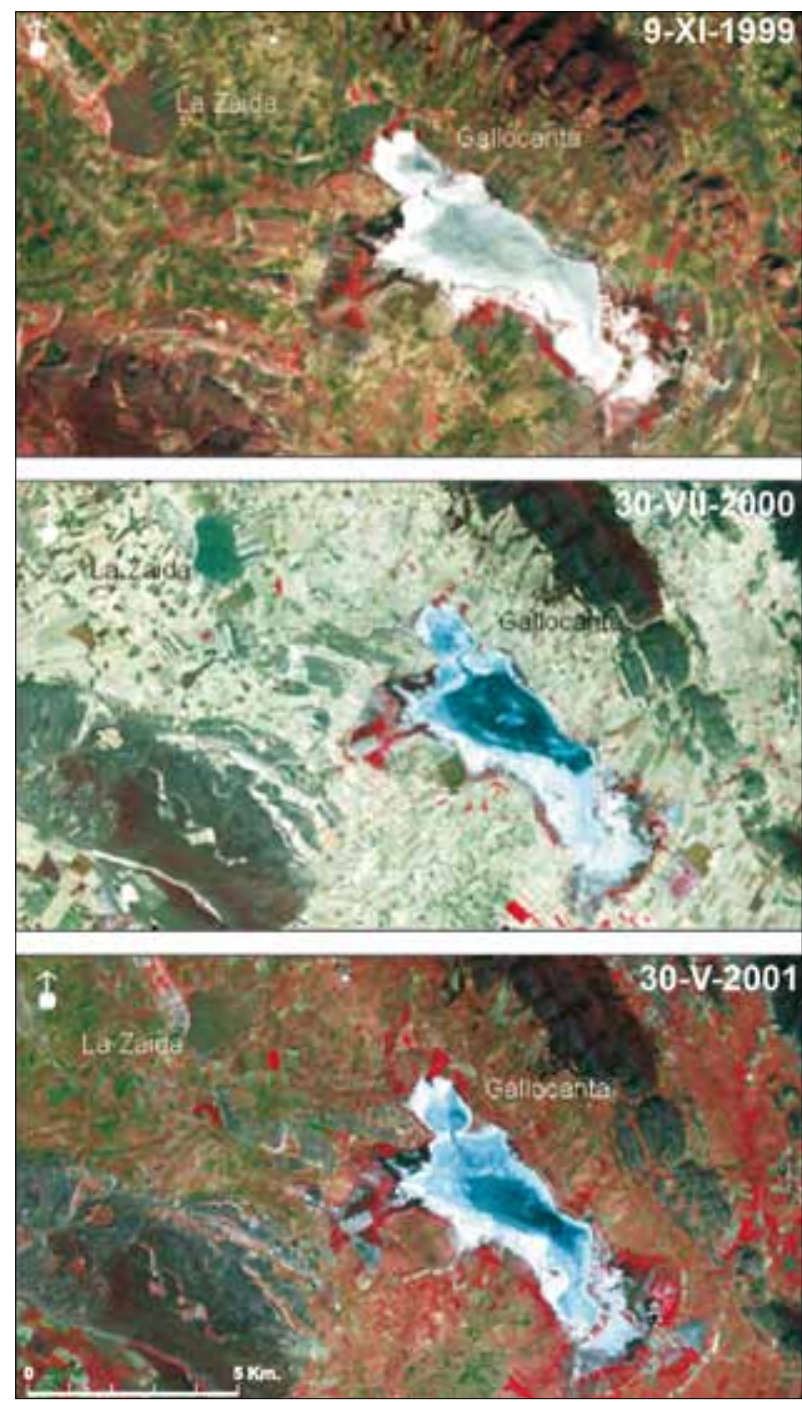

FIG. 4. Imágenes Landsat, falso color 4-3-2 (R-V-A). Estas imágenes corresponden a las fechas en las que la laguna de Gallocanta está más seca. En todas ellas, parte de la superficie está cubierta de sales (color blanco); los tonos azulados reflejan la humedad edáfica, pero sin lámina de agua superficial. La alimentación cárstica de la laguna da lugar a que sea el otoño el período del año con menor aporte hídrico, por lo que la laguna muestra mayor superficie salina. La laguna de la Zaida está cultivada y en su mitad oriental se distinguen las prácticas de laboreo.

También las imágenes en las que se transforman los colores primarios rojo, verde y azul (RVA) a hue (tono), saturación e intensidad (HSI) permiten identificar y delimitar bien los humedales y establecer diferencias en la cantidad de agua de cada uno ellos, al menos de forma comparativa. Así en azul claro se reflejan las lagunas con alturas mayores de agua y en violeta las lagunas muy someras y los suelos saturados. Estas imágenes son las úni- 


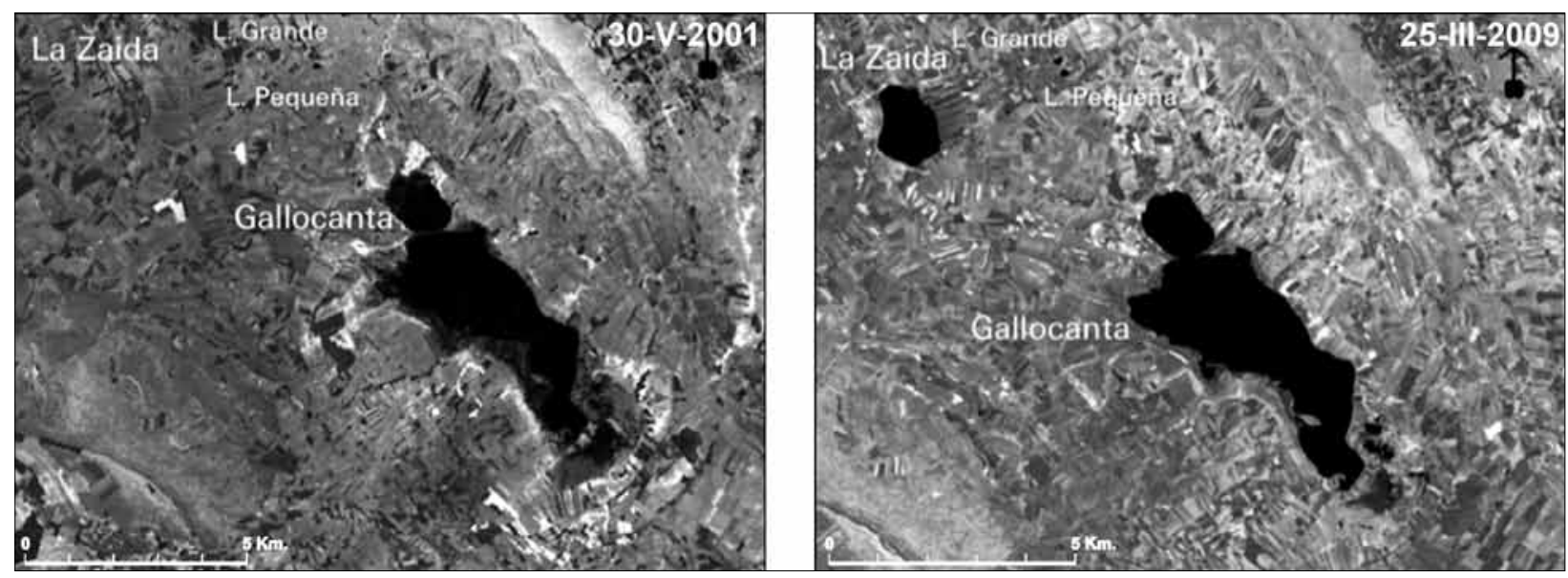

FIG. 5. NDVI aplicado a las imágenes Landsat. El color negro del vaso lagunar indica la ausencia de eutrofización. En color blanco la vegetación natural y los cultivos.

cas en las que es posible discriminar claramente los suelos desnudos de los cubiertos por eflorescencias salinas (blanco). La alta reflectividad de las dos tipologías (suelos con eflorescencias salinas y desnudos) se traducen en colores muy blancos en otras combinaciones de bandas o índices, lo que dificulta su identificación. (Fig. 6)

Además del análisis visual de las imágenes se han analizado los valores espectrales de los canales visibles e infrarrojos próximos y medio de todas las fechas para dos puntos de la laguna, con los mayores y menores valores de humedad, situados en la mitad norte de la laguna (próximo a los «ojos») y en la mitad sur respectivamente. (Fig. 7)

De estos perfiles espectrales se obtienen los siguientes resultados:

- Los valores espectrales más altos corresponden, evidentemente, a los sectores más secos, situados en todas las fechas al sur de la laguna, en los lugares más alejados a las surgencias de agua subterránea. De ellos destacan las fechas de 2000 (verano) y 2001 (primavera) con valores muy altos en todas las bandas. Los valores próximos a 250 en el visible indican la presencia de sales en superficie y en las bandas infrarrojas señalan la ausencia de agua en todo el vaso lagunar.

- Por el contrario, los valores digitales más bajos, característicos de humedales con agua, corresponden a los sectores húmedos de las imágenes de 1987 , 2009 y 2010. En estas fechas, los valores digitales de los canales infrarrojos 5 y 7 son próximos a cero, mientras que el valor más alto lo tiene el canal azul, lo que indica una capa profunda de agua. La delimitación exacta de la altura de agua es com- pleja por encima de los $80-90 \mathrm{~cm}$ de altura, por lo que es difícil establecer sólo con las imágenes comparaciones de altura precisas sin datos de campo.

- Los perfiles espectrales de las fechas de 1999, 2005 y 2011 son característicos de aguas someras $(10-30 \mathrm{~cm})$ o suelos saturados $(<10 \mathrm{~cm})$, por lo que se sitúan en una posición intermedia entre años muy secos (2000 y 2001) y años muy húmedos (2009 y 2010).

- Los bajos valores digitales de la banda 4 en casi todas las lagunas en las fechas analizadas indican que las aguas no están contaminadas, sin problemas de eutrofización.

- Aunque las imágenes de otoño ofrecen visualmente mucha información, ya que se detectan bien las sales, el análisis espectral es más confuso puesto que la menor altura solar ofrece valores bajos en todas los canales y muestra muy poca diferencia entre las distintas fechas y puntos seleccionados.

Por último, para comparar la evolución de los humedales se han hecho tres clasificaciones supervisadas de las imágenes de primavera de los años 1987, 2001 y 2009 seleccionando siete categorías de cubiertas del suelo: agua profunda, agua somera, sales, cultivos, suelo desnudo, suelo saturado en agua y vegetación natural (Fig. 8). Los porcentajes de cada una de las coberturas del suelo se resumen en el cuadro II.

Los resultados más destacados de estas clasificaciones son:

- Las imágenes de 1987 y 2009 muestran superficies y profundidades de agua muy parecidas. Se 


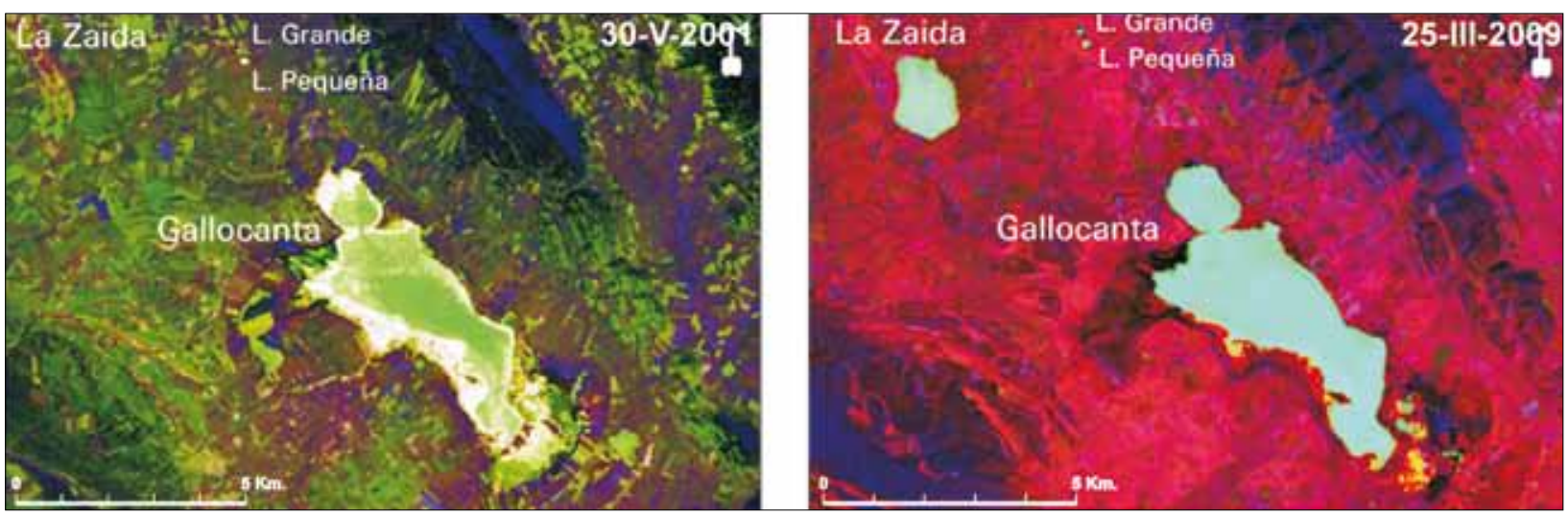

FIG. 6. Transformación de la imagen HSI. La imagen de 2001, con la laguna seca, muestra tonos verdes, similares al suelo del entorno. Por el contrario, en 2009, esta transformación resalta en azul claro la superficie ocupada por agua.

reconoce la extensa y más profunda laguna de Gallocanta (color azul oscuro) con límites bien definidos y un entorno amplio de suelo inundado (color gris). Se reconoce la laguna de La Zaida que se nuestra en ambas fechas como laguna somera sin variaciones en su vaso lagunar. También es posible reconocer dos lagunas pequeñas (la Grande y la Pequeña) al norte de Gallocanta, con mayor cantidad de agua en 2009.

- En la imagen de 2001 destaca el gran stress hídrico en todos los humedales. En la imagen obtenida no es posible reconocer ninguna de las tres lagunas menores, ya que los vasos lagunares están cubiertos parcialmente de vegetación.

- La laguna de Gallocanta queda reducida en 2001 a aguas muy someras y un gran entorno de eflorescencias salinas. Esta imagen es representativa de los años secos de la década de 1990 y primeros años del siglo Xxi. Aunque las sales son comunes en la estación estival, en primavera sólo aparecen en aquellos años más secos (2001), debido a que en esta comarca las precipitaciones máximas anuales se producen en esta fecha.

- Las notables diferencias entre los contenidos de agua en los vasos lagunares quedan reflejadas en los porcentajes del cuadro II. Así, las superficies de aguas profundas y someras son similares en 1987 y 2009 (3,75 y 0,62 \% y 4,08 y $1,0 \%$ respectivamente). El agua profunda está prácticamente ausente en la imagen de $2001(0,20 \%)$ y el agua somera, sólo visible en el vaso lagunar de Gallocanta, alcanza un 2,83\%, por lo que hay una marcada pérdida de superficie inundada.

- En el cuadro II también destacan las diferencias en las superficies ocupadas por suelo saturado. La máxima extensión se produce claramente en la fecha más reciente $(14,54 \%$ en 2009 , más del doble que en 1987) y hay un intenso retroceso de la superficie ocupada por suelo saturado en 2001 $(2,61 \%)$. Es evidente que esto conlleva en 2001 el incremento considerable de los porcentajes de sales, inapreciables en las otras fechas. La vegetación natural ha disminuido en la última fecha. Por otra parte, hay una marcada diferencia en el porcentaje de cultivos y suelos desnudos o con poca vegetación, debido a que en el área se aplica el sistema de año y vez.

\section{CONCLUSIONES}

Aunque en los primeros años del siglo XXI se hablaba de la posible desaparición de la laguna de Gallocanta debido al «cambio climático», ya que llegó a estar prácticamente seca durante algunos años, a partir de 2003 se ha recuperado temporalmente a niveles similares de los años ochenta del pasado siglo. Sin embargo, las mayores explotaciones de las aguas superficiales y subterráneas, hacen muy difícil volver a los niveles de máximos registros de los años 70, de 1,5 a $2,25 \mathrm{~m}$.

El uso conjunto de imágenes del satélite Landsat y datos de campo permite hacer un seguimiento continuo de la evolución de la laguna. Las oscilaciones temporales (intraanuales e interanuales) en su lámina de agua son coincidentes con las fluctuaciones de años meteorológicamente secos y húmedos y, con las variaciones en el uso de las aguas de la cuenca. Las elevadas precipitaciones de los dos años húmedos recientes, 2009 y 2010, han per- 


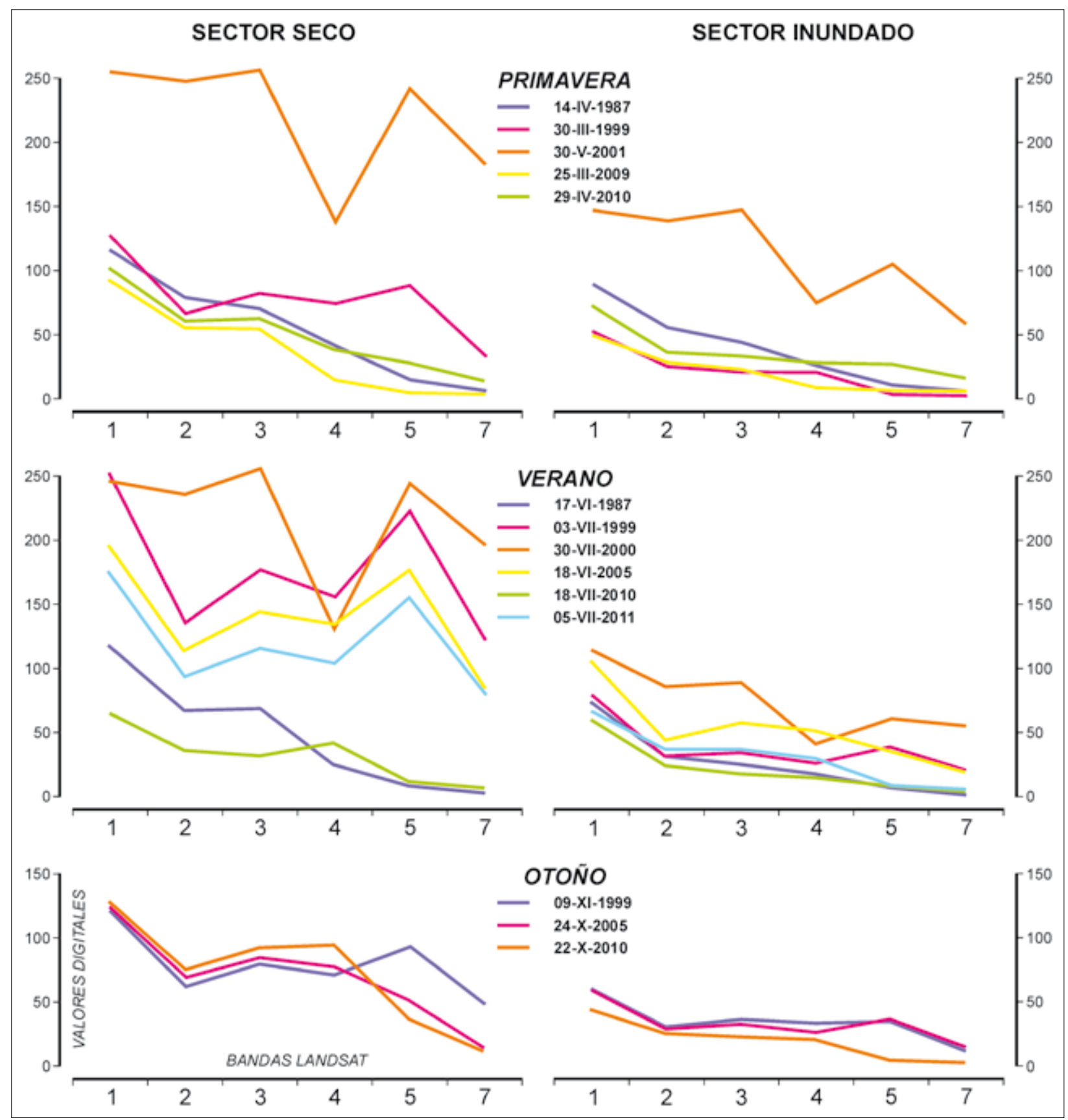

FIG. 7. Perfiles espectrales en dos sectores de la laguna de Gallocanta.

mitido recuperar una altura de agua en la laguna bastante elevada, que oscila de 1,15-0,90 m en el máximo anual y no ha descendido de $0,3 \mathrm{~m}$ hasta la fecha actual.

A partir de las imágenes Landsat la laguna de Gallocanta es claramente identificable en cualquier fecha, aunque presente fases de inundación $(1987,2009$ y 2010) y desecación muy marcadas (2000 y 2001) correspondientes a años húmedos y secos.

La ventaja de la utilización de las imágenes Landsat frente al dato puntual es la posibilidad de cartografiar con precisión la superficie ocupada por sales, el área inundada, el tipo de alimentación hídrica (las surgencias de 

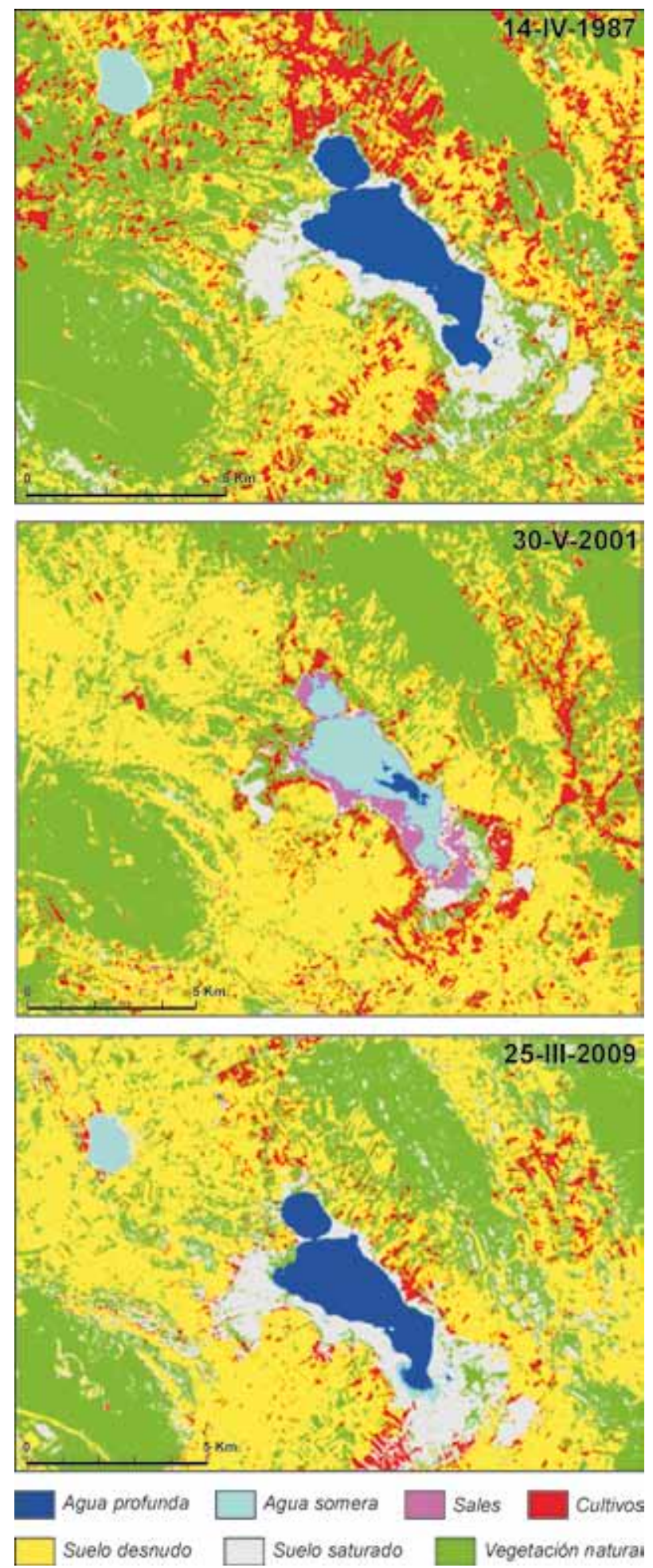

FIG. 8. Clasificaciones supervisadas.
Cuadro II. Superficie en porcentaje de las cubiertas del suelo

\begin{tabular}{|c|c|c|c|}
\hline Clases & $\% 1987$ & $\% 2001$ & $\% 2009$ \\
\hline Agua profunda & 3,75 & 0,20 & 4,08 \\
\hline Agua somera & 0,62 & 2,83 & 1,00 \\
\hline Sales & 0,00 & 1,56 & 0,00 \\
\hline Suelo saturado & 6,94 & 2,61 & 14,54 \\
\hline Suelo desnudo & 39,43 & 12,09 & 44,29 \\
\hline Vegetación natural & 40,75 & 45,50 & 31,08 \\
\hline Cultivos & 8,51 & 35,02 & 5,02 \\
\hline Total & 100 & 100 & 100 \\
\hline
\end{tabular}

Fuente: elaboración propia.

agua subterránea y los aportes superficiales temporales) y la presencia o no de aguas eutrofizadas.

En relación a la altura del agua la interpretación visual y digital de las imágenes permite estimar si hay agua o no y su altura aproximada hasta $1 \mathrm{~m}$, pues la gran absorción de la radiación electromagnética por parte del agua ofrece en humedales interiores valores muy similares a partir de esa altura. Sin duda, la precisión del dato de campo es fundamental para corroborar los valores obtenidos por los sensores y para aclarar las interferencias que puedan emitir la presencia de algas, turbiedad o sales en láminas de agua inferiores a $1 \mathrm{~m}$.

De todos los tratamientos digitales realizados a las imágenes el que mejor permite analizar los cambios en la laguna y suelos próximos es el HSI (hue, saturación e intensidad). Esta mejora espectral delimita con claridad la superficie inundada o seca y permite definir el carácter somero o profundo de un humedal en un momento dado.

Los valores espectrales identifican claramente los suelos con sales en superficie durante los periodos más secos (valores digitales muy altos en los canales del visible) y los saturados en los más húmedos. Cuando la lámina de agua alcanza mayor altura los valores son más altos en el canal azul, llegando a ser prácticamente cero en los canales infrarrojos.

Las clasificaciones supervisadas en diferentes años han permitido cartografiar las variaciones espaciales y temporales de los suelos salinos y de las áreas inundables y medir los cambios en su extensión.

Por todo ello, las imágenes Landsat resultan idóneas para el seguimiento y control de humedales interiores de tamaño medio y grande, por encima de 1100 ha de superficie. 


\section{BIBLIOGRAFÍA}

$<$ http://oph.chebro.es>.

AL-KHAIER, F. (2003): Soil salinity detection using satellite remote sensing. Thesis for the degree of Master of Science, ITC, Enschede, $70 \mathrm{pp}$.

Catañeda, C., y J. Herrero (2009): «Teledetección de cambios en la laguna de Gallocanta», en M. ${ }^{a}$ A. Casterad y C. Casteñeda (eds.): La laguna de Gallocanta. Medio natural, conservación y teledetección. Memorias de la Real Sociedad Española de Historia Natural, vII, pp. 105-128.

Chuvieco, E. (2010): Teledetección ambiental: la observación de la Tierra desde el espacio. Ariel, Barcelona.

Сомín, F. A., X. Rodó y P. Comín (1992): «Lake Gallocanta (Aragón, NE Spain ): a paradig of fluctuation and different scales of time». Limnetica, 8, pp. 79-96.

DehaAn, R., y G. TAYlor (2002): «Field-derived spectra of salinized soils and vegetation as indicators of irrigation-induced soil salinization». Remote Sensing of Environment, vol. 80, pp. 406-417.

díaz de Arcaya, N., C. Castañeda, J. Herrero y J. A. LoSADA (2005): «Cartografía de coberturas asociadas a las fluctuaciones de la laguna de Gallocanta». Revista de Teledetección, 24, pp. 61-65.

Dwivedi, R., K. SReenivas y K. V. Ramana (1999): «Inventory of salt-affected soils and waterlogged area: a remote sensing approach». Int.J. Rem. Sens., 20, pp. $1.589-1.599$.

García Rodríguez, M. ${ }^{a}$ P., y M. ${ }^{a}$ E. Pérez González (2001): «Variación estacional de los niveles de agua en la llanura de Gallocanta (Zaragoza-Teruel)», en J. Rosell Urrutia y J. A. Martínez Casasnovas (coords.): Teledetección, medio ambiente y cambio global. Universidad de Lleida, pp. 338-340.

- M. ${ }^{a}$ E. Pérez González y J. J. Sanz Donaire (2006): «Variabilidad hídrica y edáfica de humedales interiores a partir de imágenes Landsat (TM у ЕTM+)». Estudios Geográficos, LXVII, 260, pp. 57-78.

Gracia Prieto, F. J. (1993): «Fisiografía de la laguna de Gallocanta y su cuenca». Xiloca, 11, pp. 177-204.

- (2009): «Geología y geomorfología de la laguna de Gallocanta», en M. ${ }^{a}$ A. Casterad y C. Casteñeda (eds.): La laguna de Gallocanta. Medio natural, conservación y teledetección. Memorias de la Real Sociedad Española de Historia Natural, vII, pp. 61-78.

Hodgson, M. E., J. R. Jensen, H. E. Mackey Jr. y M. C.
COULTER (1987): «Remote sensing of wetland habitat: a wood stork example». Photogrammetric Engineering and Remote Sensing, 53, pp. 1.075-1.080.

IGN-Plan Nacional de Teledetección (2011): PNT_landsat-5_TM_200031/32_2005-2011_ geo_ xsbic_ etrs89_hu30_gsd25_std.

Jong, S. M. (1994): Applications of Reflective Remote Sensing for Land Degradation Studies and Mediterranean Environment. Netherland Geo-Geographical Studies 177. Thesis. Fac. Geographical Sciences, Utrecht University. 237 pp.

Косн, M., T. Schmid, J. Gumuzzio y P. Mather (2001): «Synergetic use of hyperespectral and multispectral data for the study of semi-arid wetland degradation in Spain». RSPS Conference, Londres.

Martín Escorza, C., y L. Alcalá (1999): «Rasgos y tendencias en el clima de Teruel (España)». Bol.R. Soc. Hist. Nat. (Sec. Geol.), 95 (1-4), pp. 5-14.

nasa Landsat Program (2011): Landsat tm p200/r03132/1987-2005-етм/тм-EarthSat-Orthorectified. USGS, Sioux Falls.

Patience, N., y V. V. KLemas (1993): Wetland funtional health assessment using remote sensing and other techniques: literature search. NOAA Technical Memorandum NMFS-SEFSC-319, $114 \mathrm{pp}$.

Pérez González, M. ${ }^{a}$ E., M. ${ }^{a}$ P. García RodríGuez y J. J. SAnz Donaire (2009): «Características hídricas y microclimáticas de la laguna de Gallocanta», en M. ${ }^{a}$ A. Casterad y C. Casteñeda (eds.): La laguna de Gallocanta. Medio natural, conservación y teledetección. Memorias de la Real Sociedad Española de Historia Natural, vII, pp. 129-146.

QingXi, T., Z. LANFen, W. Jinnian y Z. Bing (1997): «Study on the wetland environment by airborne hyerspectral remote sensing». Third International Airborne Remote Sensing Conference and Exhibition, vol. 1, Copenhague 1, pp. 67-74.

Reese, H. M., T. M. Lillesand, D. E. Nagel, J. S. Steward, R. A. Goldmann, T. E. Simmons, J. W. ChiPMAN y P. A. TESSAR (2002): «Statewide land cover derived from multiseasonal Landsat TM data. A retrospective of the Winscland Project». Remote Sensing of Environment, vol. 82, 2-3, pp. 224-237.

Schmid, T. F. (2004): Integrated Remote Sensing approach to detect changes in semi-arid wetland areas in central Spain. Tesis Doctoral. Universidad Autónoma de Madrid, 193 pp. 